\title{
UTILIZATION OF WASTE HEAT FOR PRODUCTION OF ELECTRICITY USING DIFFERENT THERMOELECTRIC DEVICES
}

\author{
MRS. SEEMA. V. AWARE ${ }^{1} \&$ DR. V.V.AWARE ${ }^{2}$ \\ ${ }^{I}$ Assistant Professor, College of Agricultural Engineering and Technology, Dr. BSKKV, Dapoli, India \\ ${ }^{2}$ Professor, College of Agricultural Engineering and Technology, Dr. BSKKV, Dapoli, India
}

\begin{abstract}
A Thermo Electric Generator (TEG) can be used to convert waste heat energy into electrical power. Vast amount of heat is rejected from industry, manufacturing plants and power utilities as gases or liquids at temperature which are too low to be used in conventional generating units $\left(<450^{\circ} \mathrm{K}\right)$. The thermoelectric power generators can offer a potential alternative of electricity generation powered by waste heat energy. Similarly, this can be used for power generation from household chullas, gasifiers etc. Though, the power generated is small, it can be stored in the battery for the further use.

KEYWORDS: Heat, Electricity, Thermoelectric devices \& Module
\end{abstract}

Received: Apr 06, 2020; Accepted: Apr 27, 2020; Published: Jun 02, 2020; Paper Id.: IJASRJUN20209

\section{INTRODUCTION}

In recent years, an increasing concern of environmental issues of emissions, in particular, global warming and the limitations of energy resources has resulted in extensive research into novel technologies of generating electrical power. Thermoelectric power generators have emerged as a promising alternative green technology due to their distinct advantages. Thermoelectric power generation offer a potential application in the direct conversion of waste-heat energy into electrical power where, it is unnecessary to consider the cost of the thermal energy input.

In the generation of thermoelectric power using waste heat, two dissimilar materials are connected to each other at two points to form an electric circuit, and the two junctions are maintained at different temperatures then, depending on the thermoelectric properties of the two materials, a current will flow in the electric circuit. Disalvoet al., (1999) mentioned that a ThermoElectric Generator (TEG) can be used to convert waste heat energy into electrical power. Such devices have the advantage of containing no moving parts, but low efficiencies have limited their use to speciality applications. The major drawback of thermoelectric power generator is their relatively low conversion efficiency -typically $5 \%$ (Rowe, 1998). This has been a major cause in restricting their use in electrical power generation to specialized fields with extensive applications.

The principles of thermoelectric devices are reviewed and strategies for increasing the efficiency of novel materials are explored. Improved materials would not only help to cool advanced electronics but also provide energy benefits in refrigeration. It will automatically enhance the energy conversion efficiency.

Most of the recent research activities on applications of thermoelectric power generation have been directed towards utilisation of industrial waste heat. Vast amount of heat is rejected from industry, manufacturing plants and power utilities as gases or liquids at temperature which are too low to be used in conventional generating units $\left(<450{ }^{\circ} \mathrm{K}\right)$. 
Rodrigo et al. (2004) observed that TEC converted the heat coming from the cooking stove into electricity and stored in a battery. In this large-scale application, thermoelectric power generators offer a potential alternative of electricity generation powered by waste heat energy. This would contribute to solve the problem of energy crisis and at the same time it would help to reduce global warming. Similarly, this can be used for power generation from household chullas, gasifiers etc.

\section{MATERIAL AND METHODS}

The present investigation entitled 'study of thermo electric power generation system using cooking stove' was undertaken at College of Agril. Engineering and Technology, Dapoli. The power outputs of Thermoelectric (TE) modules viz., TEC112706 and SP 1848 at different temperature differences were taken with following steps.

- $\quad$ Recording the surface temperature differences of TE modules viz., TEC1-12706 and SP 1848 when supplied with DC source.

- $\quad$ Recording the temperature readings radiated as waste heat from the L.P.G cooking stove, tube-in insulated gasifier and non-insulated gasifier.

- Development of cook stove prototype having flat surface.

- Development of cooling container.

- $\quad$ Recording of power output from the cook stove prototype using TE module.

\subsection{Materials}

The following materials were used for the study of thermoelectric power generation system.

\begin{tabular}{|l|l|}
\hline $\begin{array}{l}\text { 1. Thermoelectric module (Two TEC1- } \\
12706 \text { and One SP-1848) }\end{array}$ & 10. Thermometer \\
\cline { 2 - 2 } & 11. Aluminum plate \\
\hline 2. Cold source and hot source & 12. Tin plate \\
\hline 3. Iron plate & 13. M- seal \\
\hline 4. Glass wool & 14. Heat sink \\
\hline 5. Thermal grease & 15. Load \\
\hline 6. Cello tape & 16. Joule thief circuit \\
\hline 7. Fevicol SR 998 & 17. Binder clip \\
\hline 8. Soldering iron & 18. Nut bolts \\
\hline 9. Multimeter & \\
\hline
\end{tabular}

\subsubsection{Thermoelectric Electric Modules (TEC1-12706 and SP 1848)}

In thermoelectric power generator, heat energy is converted in electricity. It works on Seebeck effect. The devices used for this energy conversion are ThermoElectric Generators TEG), and it has immediate potential in recovering the waste heat. The thermoelectric module used were TEC1-12706 (two numbers) and SP 1848 (one). The TEGs have many advantages such as no moving mechanical parts, long-lived, quiet, environmentally friendly and requiring little maintenance. The thermoelectric generators recover useful energy by the function of thermoelectric modules which can convert waste heat energy into electricity from automotive exhaust. In the actual operation, the electrically connected thermoelectric modules are operated under temperature mismatch conditions. The problem of decreased power output causes due to the inhomogeneous temperature gradient distribution on heat exchanger surface. By using thermoelectric generators, it is 
possible to develop independent electric energy source in burning and heating systems in households and industrial heating.

\section{METHODS}

The following steps were undertaken for using the thermoelectric module for power generation.

\subsection{Recording the Power Output of TEC1-12706 by Supplying Different Temperature Differences}

The thermoelectric module TEC1-12706 placed on iron plate was supplied with hot source using candle. Above the TEC112706 aluminium plate filled with ice was used as cooling source and the temperature difference was created, the different temperatures were recorded using infrared thermometer. Load of $1 \Omega$ was connected in series. Two multimeters were connected to read the voltage and current at the output and the power output was calculated by multiplying voltage to the current.

\subsection{Recording the Power Output of SP-1848 by Supplying Different Temperature Differences}

The same procedure was followed for recording power output of TECSP-1848.

\subsection{Development of Cook Stove Prototype having Flat Surface}

Since the TE module was flat surfaced and the gasifier was having circular surface, the contact area between two was not enough. Hence, to increase the surface area of contact, the cook stove with flat surface was necessary to design. Therefore, an empty oil tin container which was having four sides with flat surface was taken for the design. The oil tin container was having dimensions $21 \mathrm{~cm} \times 21 \mathrm{~cm} \times 40 \mathrm{~cm}$. A hole of diameter $12.4 \mathrm{~cm}$ was made in the centre and $1 \mathrm{~cm}$ above the base of the container. This hole was for the insertion of biomass and wood as fuel. In order to utilize the waste heat from the constructed cooking stove, an iron plate was attached of $28.5 \mathrm{~cm} \times 20.4 \mathrm{~cm}$ and $0.5 \mathrm{~cm}$ thick was attached on its surface using nut bolts. The cook stove is shown at Figure 1.

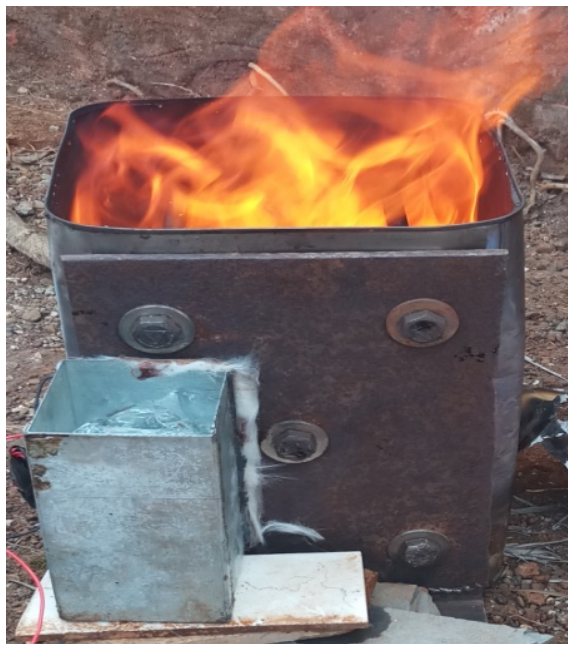

Figure 1: Cook Stove with Cooling Container.

\subsection{Development of Cooling Container}

A MS container of $15 \mathrm{~cm} \times 8 \mathrm{~cm} \times 8 \mathrm{~cm}$ from $0.125 \mathrm{~cm}$ thick tin plate was fabricated by welding, so as to give cooling effect to one side of the thermoelectric modules using ice when the readings from the prototype were taken. M-seal was used to make it leak-proof, which took 30 minutes for setting. The cooling container is shown in Figure 2. 


\subsection{Power Output of TEC1 12706 and SP-1848 connected in Series}

Power output of two TEC1 12706 and one SP-1848 connected in series was recorded. Thermoelectric module connected in series and pasted on MS plate is shown in Figure 2

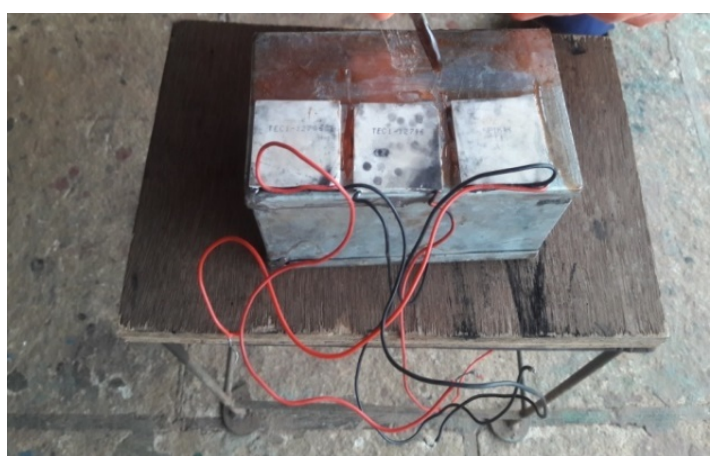

Figure 2: Combined Thermoelectric Module Pasted on the MS Plate and connected in Series

\section{RESULTS AND DISCUSSIONS}

\subsection{The Power Output from Module TEC1-12706 at Different Temperature Differences}

The relationship between temperature difference and power output for module TEC1-12706 is given in Fig. 3.

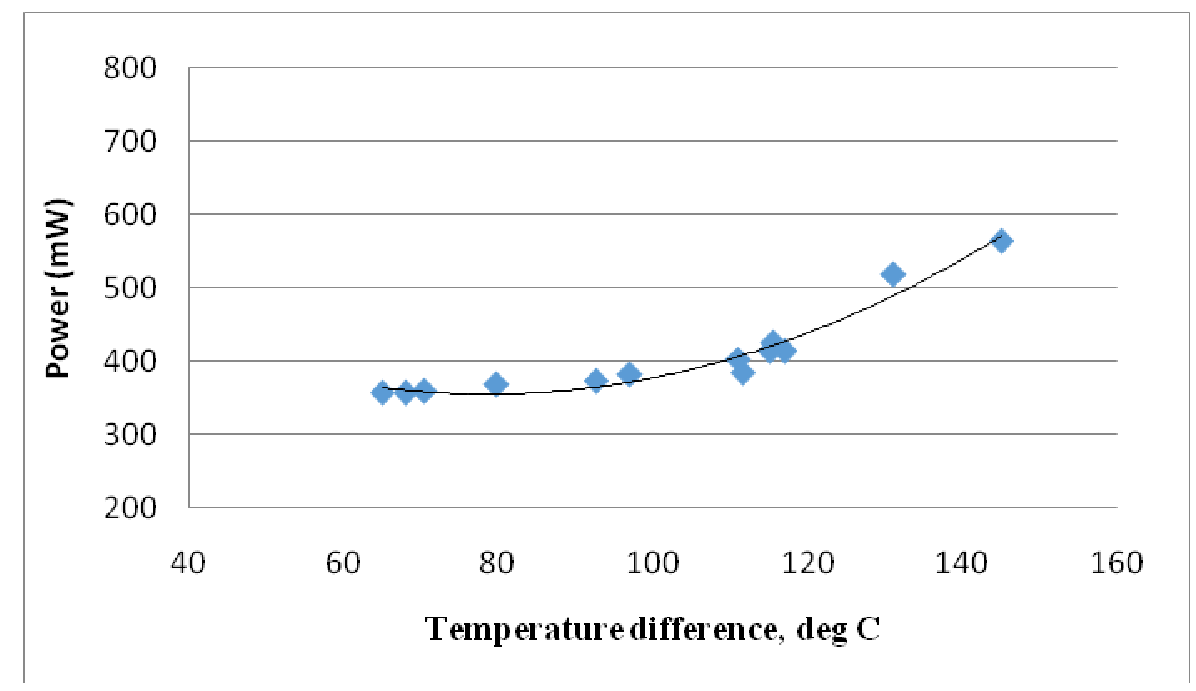

Figure 3: The Relationship Between Temperature Difference and Power Output for TEC1-12706.

The power output for module TEC1-12706 at various temperature differences was recorded. The temperature difference was in the range of 65 to $145^{\circ} \mathrm{C}$. Whereas the power output was in the range of 357 to $564 \mathrm{~mW}$. Hence, the maximum power output was $564 \mathrm{~mW}$ at $145^{\circ} \mathrm{C}$.

\subsection{Power output for SP-1848 by Supplying Different Temperature Differences}

The power output for module SP-1848 at various temperature differences were recorded. The relationship between temperature difference and power output for module SP-1848 is as given in Figure 4. 


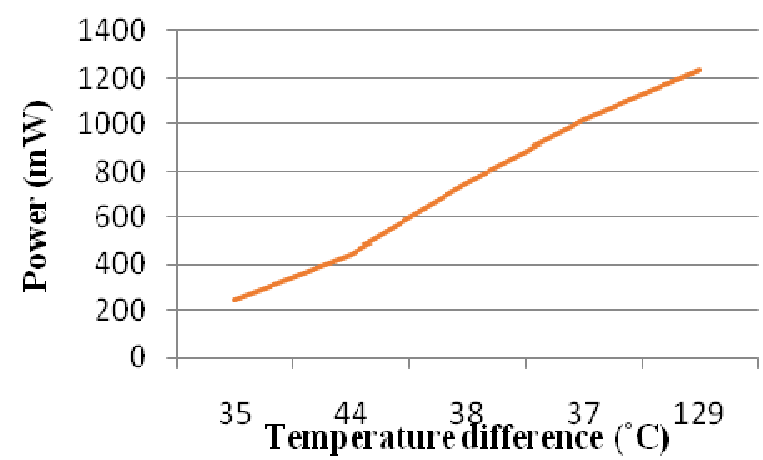

Figure 4: The Relationship Between Temperature Difference and Power Output for SP1848.

The temperature difference was in the range of 35 to $129^{\circ} \mathrm{C}$. Whereas, the power output was in the range of 247 to $1239 \mathrm{~mW}$. Hence, maximum power output was $1239 \mathrm{~mW}$ at $129{ }^{0} \mathrm{C}$.

\subsection{The Power Output from the Cook Stove Prototype using TE Module}

The two TEC 1-12706 and one SP 1848 of size $4 \mathrm{~cm} \times 4 \mathrm{~cm} \times 0.4 \mathrm{~cm}$ were stuck on one side of the tin container facing close to the edges and were attached on the container using thermal grease. Thermal grease required 30 minutes time for proper setting. The glass wool was glued on remaining surface using adhesive (Fevicol SR 998). The glass wool was handled very carefully with gloves and was applied only on one side of the container on which the TE module were attached to provide insulation. Then, the wires were connected in series by soldering iron. The thermoelectric modules connected in series are shown in figure 2. Then, the cooling tin container was filled with ice and the container side having TE modules was attached to the iron plate of the cook stove prototype having maximum possible contact. The cook stove prototype was then filled with woods with few drops of diesel sprinkled over it and was ignited matchstick. The multimeter was used to measure the voltage and current from the circuit, after maintaining the temperature difference. The temperature was measured using infrared thermometer of the cold and hot side. Thus, the power was calculated by multiplying voltage with the current. Voltage booster was connected at the output of the circuit and the voltage was measured along with the current. LED strip of $12 \mathrm{~V}$ and $24 \mathrm{~V}$ were connected individually in series and it was glowed using the waste heat from the cooking stove. The temperature difference and the corresponding power output are given in the following table.

Table 1: The Temperature Difference and Corresponding Power Output for the TEC Module

\begin{tabular}{|c|c|c|c|c|c|}
\hline \multirow{2}{*}{$\begin{array}{c}\text { Hot } \\
\text { Temperature } \\
\left({ }^{\circ} \mathrm{C}\right) \\
\end{array}$} & \multirow{2}{*}{$\begin{array}{c}\text { Cold Temperature } \\
\left({ }^{\circ} \mathrm{C}\right)\end{array}$} & \multirow{2}{*}{$\begin{array}{l}\text { Temperature difference } \\
\left({ }^{\circ} \mathrm{C}\right)\end{array}$} & \multicolumn{3}{|c|}{ Power output, mW } \\
\hline & & & Current (mA) & $\begin{array}{c}\text { Voltage } \\
\text { (V) }\end{array}$ & $\begin{array}{c}\text { Power, } \\
\text { mW }\end{array}$ \\
\hline 150 & 7 & 143 & 275 & 367 & 4958 \\
\hline 190 & 8.5 & 181.5 & 280 & 396 & 5575 \\
\hline 250 & 9.01 & 240.99 & 296 & 409 & 6257 \\
\hline 275 & 10 & 265 & 300 & 413 & 6636 \\
\hline
\end{tabular}

The relationship between temperature difference and corresponding power output is for two numbers TEC112706 and one number SP-1848 is given in Figure 5. 


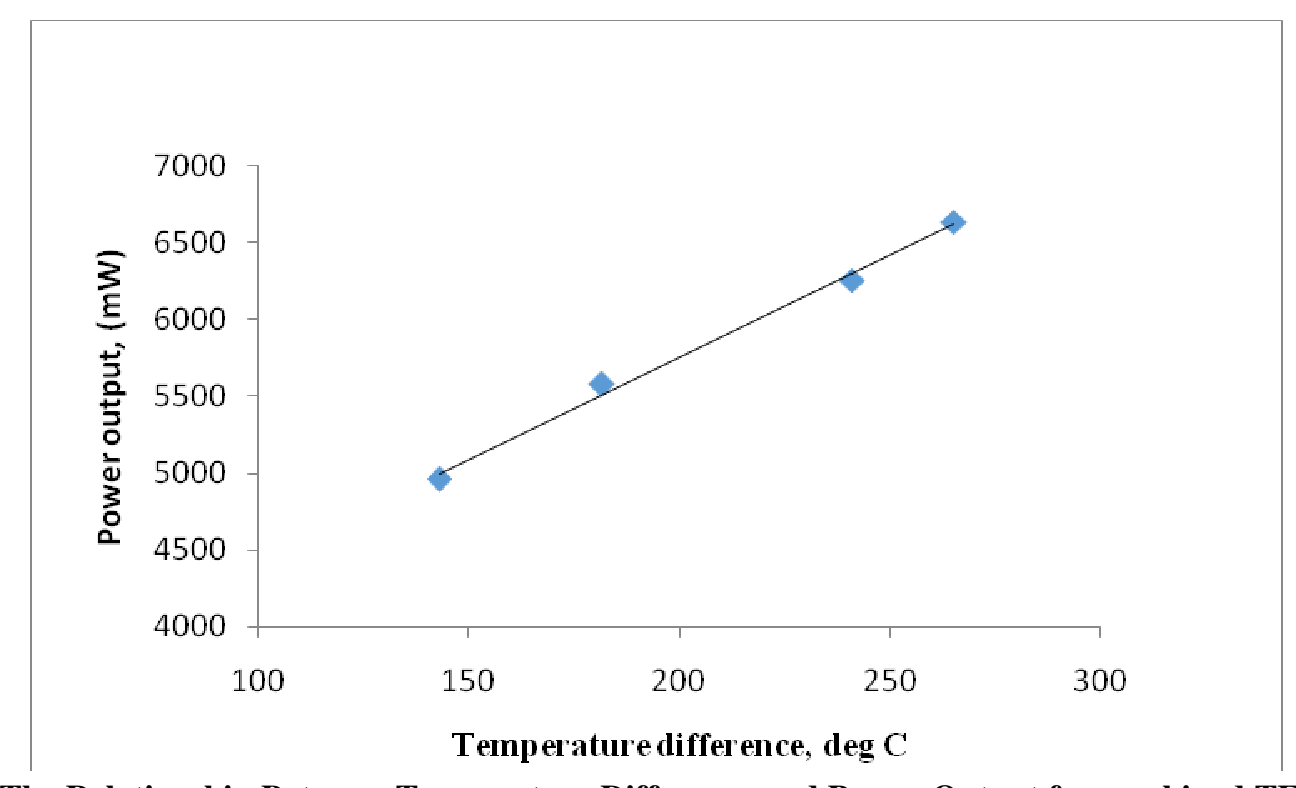

Figure 5: The Relationship Between Temperature Difference and Power Output for combined TEC Module.

The temperature difference range for the combined TEC module i.e. two TEC1-12706 and one SP-1848 was 143 to $265^{\circ} \mathrm{C}$ whereas, the power output was in the range of 4958 to $6636 \mathrm{~mW}$.

\section{FINDINGS}

- The maximum power output was $564 \mathrm{~mW}$ at $145{ }^{\circ} \mathrm{C}$ for thermoelectric module TEC1-12706, whereas, that was $1239 \mathrm{~mW}$ at $129^{\circ} \mathrm{C}$ for SP-1848.

- In case of combined thermoelectric module, i.e. two TEC1-12706 and one SP-1848 connected in series, the power output was $6636 \mathrm{~mW}$ at $265^{\circ} \mathrm{C}$ temperature.

\section{CONCLUSIONS}

The waste heat radiated from gasifiers, Chullasetc can be utilised for thermoelectric power generation using TEGs in series.

\section{REFERENCES}

1. Benziger, B., P. Anu Nair, and P. Balakrishnan. "Review paper on thermoelectric airconditioner using peltier modules." IJME 4.

2. Disalvo F. J. 1999. Thermoelectric cooling and power generation. Journal of thermoelectric effect, Vol. 28, p, 703.

3. Mahrous, A., et al. "Cooling Via Human Forearm for Multiple Sclerosis." International Journal of Mechanical Engineering (IJME) 4.6 (2015): 1-12.

4. Naidu, K. Chandra Babu, T. Sofi Sarmash, and T. Subbarao. "Preparation and characterization of nano SrTiO3 ceramics." International Journal of Physics and Research 4 (2014): 1.

5. Resan, Kadhim K., et al. "Influence of Temperature on Fatigue Life for Friction Stir Welding of Aluminum Alloy Materials." International Journal of Mechanical \& Mechatronics Engineering IJMME-IJENS 18.02 (2018).

6. Rodrigo C. M., D. G. Chandand Manansala 2004. Heat radiation approach for harnessing heat of the cook stove to generate electricity for lighting system and charging of mobile phone, IOP Conference Series: Earth and Environment Science, 2-5. 
7. Rowe D.M. 1978. Thermoelectric power generation. Journal of thermolectricconversions, Proc. IEE, Vol.125, (11) R: pp, $1113-1136$.

8. Rowe D. M., G.Min 1998. Evaluation of thermoelectric modules for power generation.Power Source; 73: 193-198.

9. Rowe D. M. 1999.Thermoelectrics an environmentally-friendly source of electrical power. Renewable Energy; 16: 1251-1265.

10. Singh S. and P. Londhe 2018.Study of thermo electric power generation system using cooking stove. B. Tech. thesis submitted to College of Agricultural Engineering and Technology, Dapoli. 

